\title{
Audiological assessment and otoacoustic emissions in patients with head and neck cancer
}

\author{
Pâmela Fukazawa1 \\ https://orcid.org/0000-0002-6007-6950 \\ Sarah da Silva Santos ${ }^{1}$ \\ https://orcid.org/0000-0002-1963-8763 \\ Raquel Caroline Ferreira Lopes Fontanelli' \\ https://orcid.org/0000-0001-6420-1133 \\ Daniela Gil ${ }^{1}$ \\ https://orcid.org/0000-0002-8647-6813
}

Universidade Federal de São Paulo UNIFESP, São Paulo, São Paulo, Brasil

Conflict of interests: Nonexistent

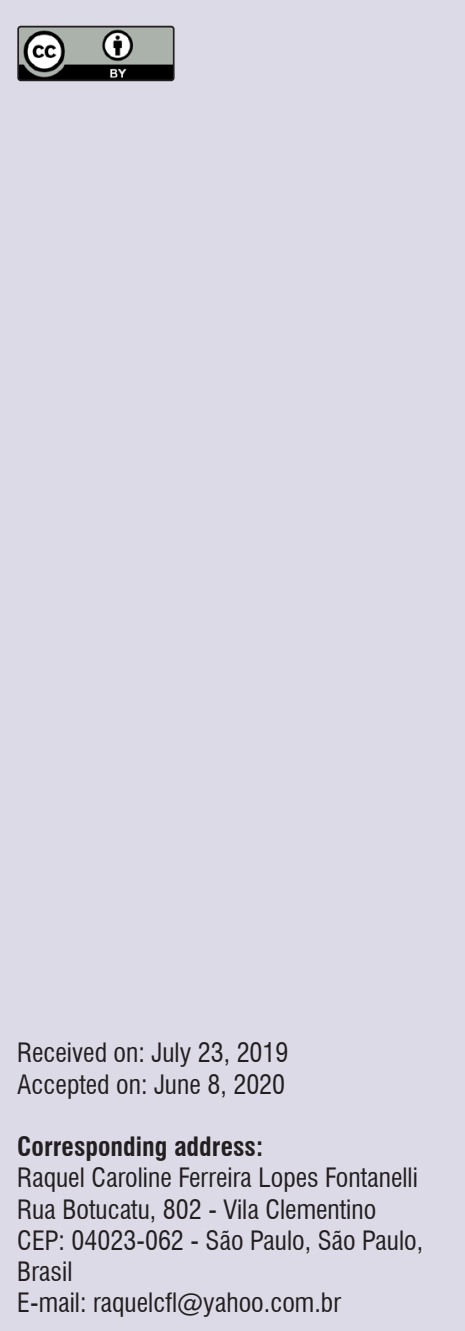

\section{ABSTRACT}

Purpose: to describe the audiological and otoacoustic emission findings in patients who had head and neck cancer and compare them with individuals without the disease.

Methods: a comparative, cross-sectional, observational study encompassing two groups: Study: individuals with a history of head and neck cancer, submitted to chemotherapy and/or radiotherapy; Control: individuals without the disease. The sample comprised 23 individuals in each group, matched for age and gender. Procedures in which the groups were compared: meatoscopy; pure-tone threshold and highfrequency audiometry; speech audiometry; transient-evoked otoacoustic emissions. Statistical tests: Pearson's chi-square; Fisher's exact; two-proportion Z-test; Wilcoxon; Mann-Whitney; Student's $t$-test.

Results: the comparison between the groups revealed statistically significant differences at the $3,6,8,10$, and $12.5 \mathrm{kHz}$ frequencies in the pure-tone threshold audiometry, with better pure-tone auditory thresholds in the control group. No significant differences were observed between the groups in the otoacoustic emissions regarding the general response and frequency band.

Conclusion: individuals with a history of head and neck cancer had higher pure-tone auditory thresholds than their controls, especially at the higher frequencies. This evidences the deleterious effect of ototoxicity on the peripheral auditory system of adults. The otoacoustic emissions were similar in the two groups.

Keywords: Hearing; Head and Neck Neoplasias; Chemotherapy; Radiotherapy; Auditory Tests 


\section{INTRODUCTION}

Cancer is a disease that results from a variety of chemical, physical, and viral factors, in most of the cases causing permanent and irreversible alterations in a certain proportion of the cells in the organism 1. According to the National Cancer Institute (Instituto Nacional do Câncer - INCA), of the Brazilian Ministry of Health, head and neck cancer ranks fifth among the most frequent neoplasias, with a worldwide incidence estimated at 780,000 new cases per year ${ }^{2}$.

Laryngeal cancer, one of the most common of those affecting the head and neck region, occurs predominantly in men $^{3}$. It represents approximately $25 \%$ of the malignant tumors affecting this region and $2 \%$ of all malignant diseases. The number of new cases is estimated at 7,350 - 6,360 in men and 990 in women - and the death toll is 4,141-3,635 men and 506 women ${ }^{2}$.

Regarding etiology, smoking stands out as the main risk factor; when it is combined with alcoholism, the risk is potentialized. There are other aggravating factors, such as family history, bad eating habits, unfavorable socioeconomic conditions, chronic inflammation of the larynx caused by gastroesophageal reflux, human papillomavirus (HPV), exposure to chemical products and pollution ${ }^{4}$.

Traditionally, cases of laryngeal cancer are treated through surgery, radiotherapy, and chemotherapy, either alone or in combination ${ }^{5}$. The surgical treatment involves the total or partial resection of the larynx, depending on how severely the lesion has affected the organ. The partial resection surgery is called partial laryngectomy ${ }^{6}$. Its purpose is to maintain the integrity of the laryngeal functions, such as ventilation, protection of the upper respiratory tract, sphincteric functions, and phonation; the greatest deficit is in swallowing. The total resection surgery, named total laryngectomy ${ }^{6}$, consists of removing the laryngeal structures, with great damage especially to phonation, due to the loss of the laryngeal voice.

In chemotherapeutic treatment, drugs such as aminoglycosides, carboplatin, vincristine, cisplatin, and others can be used ${ }^{7}$. These drugs are considered highly toxic to the auditory system ${ }^{8}$. The cisplatin, discovered by Rosenberg et al. ${ }^{9}$, is currently used with great effectiveness in the treatment of head and neck tumors. One of its side effects, though, is the degeneration of the hair cells in the basal region of the cochlea ${ }^{10}$, with the potential to impair the whole cochlea.
The hearing losses caused by ototoxic antineoplastic drugs are definitive and irreversible ${ }^{11}$. First, it affects the base of the cochlea, resulting primarily in a loss at high frequencies; therefore, the audiological assessment must include high frequencies ${ }^{12}$.

The radiotherapeutic treatment ${ }^{13}$ - which uses an ionizing radiation beam - aims to remove all tumorous cells with the least possible damage to the surrounding normal cells ${ }^{5}$. However, due to the high anatomical complexity of the head and neck region, it is difficult to exclude certain structures in the area being treated ${ }^{2}$. Since the components of the auditory system are located nearby the regions affected by head and neck cancers, they can receive radiation even though they are not the target organ - which can lead to hearing loss $^{2,7,8}$.

The oncological patients present greatly varying hearing loss results, ranging from $29 \%$ to $61 \%$ some individuals with hearing loss are even classified as normal hearing in some of the post-oncological treatment assessment criteria ${ }^{14}$. Hence, it is important to detect hearing loss early through audiological assessment procedures with high sensitivity to identify medication-induced auditory alterations ${ }^{15}$.

Hearing loss is more likely to occur when the patient is submitted to a treatment combining radiotherapy and chemotherapy ${ }^{8}$. The ototoxicity of the medications together with the radiation may cause irreversible hearing loss, either early or late, thus impairing the patient's quality of life ${ }^{11,12}$.

The patients submitted to partial laryngectomy have their glottis' histological architecture changed, causing a deficiency in glottal coaptation, which leads to vocal disorders. The main functional impacts caused by partial laryngectomy are breathy voice, low intensity, phonation difficulty, and decreased maximum phonation time. Because of these impacts, a speechlanguage-hearing therapist - whose role is to help the patient produce their best voice - is made necessary. Speech-language-hearing rehabilitation is based on adapting the functions to the anatomo-functional limits imposed by the treatment a patient was submitted to, aiming to achieve their best possible adaptation for an improved quality of life. Having their hearing preserved is a greatly important factor for such an adaptation to be successful, since it would allow the patient a better sound perception for self-monitoring, reflecting positively on the therapeutic process.

In the case of patients with head and neck cancer, oral cavity cancer, and/or who have been partially 
laryngectomized, submitted to chemotherapeutic and/ or radiotherapeutic treatment ${ }^{15-17}$, the audiological assessment and otoacoustic emissions is greatly relevant, as they identify lesions in the outer hair cells ${ }^{18-21}$. Authors point out that no statistically significant values were found for the amplitude of the otoacoustic emissions in adults submitted to carboplatin chemotherapy. Nonetheless, the audibility thresholds worsened, especially in the high frequencies ${ }^{17}$.

The audiological assessment data enables alterations to be identified, to which hearing aids can be indicated. This minimizes the impact hearing loss has on the person's quality of life, as hearing is essential to communication and so to social interaction adjustment.

Despite the growing number of people submitted to these types of surgeries and/or radiotherapy and chemotherapy every year, there is a shortage of studies in the literature regarding the auditory consequences of radiotherapy, either alone or in combination with chemotherapy.

This study aimed to compare the results of the pure-tone audiometry, high-frequency audiometry, speech audiometry, and transient-evoked otoacoustic emissions in adults with and without a history of head and neck cancer.

\section{METHODS}

This research was presented, analyzed, and approved by the Research Ethics Committee of UNIFESP (Universidade Federal de São Paulo) in its first versions under the numbers 1214/2015 and $1215 / 2015$. It was a prospective study, conducted at the Speech-Language-Hearing Department of the Universidade Federal de São Paulo, São Paulo, Brazil, in the Hearing Disorders and Human Communication Disorders courses.

This comparative, cross-sectional, observational study involved two groups - SG (study group) and CG (control group) - matched for gender and age. Initially, the protocols of the patients with head and neck cancer receiving care at the institution of origin were analyzed to comprise the SG.

The inclusion criteria for this group were patients aged between 30 and 80 years, both male and female, with type A tympanometry curve, no history of alteration in the middle ear, and a positive history of primary head and neck cancer, submitted to chemotherapy and/or radiotherapy.

The inclusion criteria for the control group were the type A tympanometry curve, no history of alteration in the middle ear, no history of cancer, and no use of ototoxic medications and/or drugs.

The exclusion criteria for both groups were evident or diagnosed cognitive and/or psychiatric alterations, a positive otologic history, and the use of hearing aid.

The convenience sample comprised 46 individuals 23 with a history of cancer, submitted to chemotherapy and/or radiotherapy; and 23 without a positive history of cancer - aged between 30 and 80 years. The control group was matched for gender and age.

The patients who met the inclusion criteria were contacted and signed the Informed Consent Form.

First, the audiological anamnesis was conducted to collect personal aspects of each patient, such as identification, previous history, and possible auditory complaints.

The following procedures were conducted: meatoscopy, pure-tone audiometry (250 to $8000 \mathrm{~Hz}$ ), high-frequency audiometry $(10,000,12,000,14,000$ $\mathrm{Hz}$ ), speech audiometry, acoustic immittance, and transient-evoked otoacoustic emissions (TEOAE).

The external acoustic meatus (EAM) was visually inspected with an otoscope to verify whether there was any outer ear obstruction.

The pure-tone threshold audiometry was conducted in a sound booth with supra-aural earphones ${ }^{22}$. The audiometric examination was made with an Itera II audiometer, beginning at the $1000 \mathrm{~Hz}$ frequency, followed by 2000, 3000, 4000, 6000, 8000, 500, and $250 \mathrm{~Hz}$ frequencies, in this order, with supra-aural earphones (TDAH-39). The auditory thresholds for the $10,000,12,000$, and $14,000 \mathrm{~Hz}$ frequencies were obtained using the same procedure of the pure-tone audiometry, with circumaural earphones (HDA-200).

The hearing was considered within normality standards when the mean of the 500, 1000, and 2000 $\mathrm{Hz}$ frequencies was better than or equal to $25 \mathrm{~dB}$. In the case of hearing loss, its degree was classified according to the method by Lloyd and Kaplan ${ }^{23}$.

The speech audiometry procedures - encompassing the Speech Reception Threshold (SRT) and Word Recognition Score (WRS) - were conducted via live voice while the patient was in the sound booth. In the WRSI, the patient was instructed to repeat monosyllable words presented at the constant level of $40 \mathrm{~dB}$ above the mean of the pure-tone thresholds at 500,1000 , and $2000 \mathrm{~Hz}$. Repeating correctly the 25 monosyllable words was worth $100 \%$; for each mistake made by the patient, $4 \%$ was subtracted from that total. Individuals without oral communication were instructed 
to point to images - bread, hand, foot, honey, salt, flower, sea, soccer goal, shovel, and tea - as required by the assessor. The total of the 20 images was worth $100 \%$; for each mistake made by the patient, $5 \%$ was subtracted from that total. The equipment used was the Itera II audiometer.

The TEOAE was picked up by a probe with a microphone placed in the external acoustic meatus, sealed with a latex tip. It was conducted in a sound booth through an llo92 device. The evoking stimulus was kept between 75 and $85 \mathrm{~dB}$ peSPL. The frequency bands surveyed were $1000,2000,3000$, and $4000 \mathrm{~Hz}$. The criteria employed to consider the presence of response in the transient-evoked otoacoustic emissions test were those of Finitzo ${ }^{24}$ : response amplitude (signal-to-noise ratio) equal to or above $3 \mathrm{~dB}$ SPL, at the frequency bands of $1000,2000,3000$, and $4000 \mathrm{~Hz}$; general reproducibility equal to or above $50 \%$; probe stability equal to or above $70 \%$; A and B wave overlap by visual inspection.

The following statistical tests were used for the comparison between the groups: Pearson's chi-square, two-proportion Z-test, Wilcoxon signed-rank test,
Mann-Whitney test, and the parametric Student's $t$-test. The significance level adopted was $p<0.05$ (5\%). The confidence intervals developed throughout the paper were considered with $95 \%$ of statistical reliability.

\section{RESULTS}

A total of 46 individuals participated in this study 23 with a history of head and neck cancer submitted to chemotherapy and/or radiotherapy, and 23 without a positive history of cancer, matched for age (Student's $t$-test, $p>0.999$ ). Their age ranged from 32 to 80 years; the mean age was 59 years; median, 58 years; standard deviation, 12.89 years; the youngest age was 32 , and the oldest, 80 years; the confidence interval was $53.73-64.88$ years.

As for the frequency distribution regarding gender and type of treatment in the groups studied, it was observed that males were predominant in the study group, as well as chemotherapy and combined treatment with radiotherapy and chemotherapy, in equal proportion. The SG and CG were matched for age and gender (Table 1).

Table 1. Characterization of the Study Group regarding gender and type of treatment

\begin{tabular}{|c|c|c|c|c|c|}
\hline Variable & Groups & Category & $\mathbf{N}$ & Frequency (\%) & p-value \\
\hline \multirow{4}{*}{ Gender } & \multirow{2}{*}{ Study Group } & Males & 14 & 60.9 & \multirow{4}{*}{$>0.999$} \\
\hline & & Females & 9 & 39.1 & \\
\hline & \multirow{2}{*}{ Control Group } & Males & 14 & 60.9 & \\
\hline & & Females & 9 & 39.1 & \\
\hline \multirow{6}{*}{$\begin{array}{l}\text { Type of treatment } \\
\text { conducted with the } \\
\text { Study Group }\end{array}$} & \multirow{2}{*}{ Chemotherapy } & Males & 3 & 37.5 & \multirow{6}{*}{0.475} \\
\hline & & Females & 5 & 62.5 & \\
\hline & \multirow[b]{2}{*}{ Radiotherapy } & Males & 5 & 71.4 & \\
\hline & & Females & 2 & 28.6 & \\
\hline & \multirow{2}{*}{$\begin{array}{c}\text { Chemotherapy + } \\
\text { Radiotherapy }\end{array}$} & Males & 6 & 75.0 & \\
\hline & & Females & 2 & 25.0 & \\
\hline
\end{tabular}

Caption: N: number of subjects. Statistical tests: Pearson's chi-square and Fisher's exact test. 
There was no statistical significance in either of the variables - i.e., the sample proved to be homogeneous for both variables. Hence, the sample comprised predominantly male adults, whose most frequent treatments were both chemotherapy and combined radiotherapy and chemotherapy. The time of treatment ranged from 6 to 36 sessions.

The comparison between the study and control groups concerning pure-tone thresholds, using Student's $t$-test, is shown in Table 2.

Table 2. Comparison between the Study Group and Control Group regarding the pure-tone auditory thresholds, in $\mathrm{dB} \mathrm{HL}$, obtained in the pure-tone threshold audiometry

\begin{tabular}{|c|c|c|c|c|c|c|c|}
\hline $\begin{array}{l}\text { Sound } \\
\text { frequencies } \\
(\mathrm{kHz})\end{array}$ & Group & Mean & SD & Median & Minimum & Maximum & p-value \\
\hline \multirow{2}{*}{0.25} & SG & 16.96 & 10.30 & 15.00 & 0.00 & 40.00 & \multirow{2}{*}{0.797} \\
\hline & CG & 16.41 & 9.87 & 15.00 & 0.00 & 50.00 & \\
\hline \multirow{2}{*}{0.5} & SG & 17.83 & 8.86 & 15.00 & 5.00 & 40.00 & \multirow{2}{*}{0.180} \\
\hline & CG & 15.22 & 9.66 & 12.50 & 0.00 & 45.00 & \\
\hline \multirow{2}{*}{1} & SG & 17.93 & 10.83 & 15.00 & 5.00 & 45.00 & \multirow{2}{*}{0.255} \\
\hline & CG & 15.33 & 11.03 & 15.00 & 0.00 & 45.00 & \\
\hline \multirow{2}{*}{2} & $S G$ & 20.33 & 14.73 & 17.50 & 0.00 & 60.00 & \multirow{2}{*}{0.814} \\
\hline & CG & 19.57 & 16.12 & 15.00 & 0.00 & 60.00 & \\
\hline \multirow{2}{*}{3} & SG & 31.09 & 20.81 & 27.50 & 5.00 & 80.00 & \multirow{2}{*}{$0.029 *$} \\
\hline & CG & 21.85 & 19.16 & 15.00 & 0.00 & 60.00 & \\
\hline \multirow{2}{*}{4} & SG & 34.24 & 21.63 & 25.00 & 5.00 & 95.00 & \multirow{2}{*}{0.151} \\
\hline & CG & 27.83 & 20.89 & 20.00 & 0.00 & 70.00 & \\
\hline \multirow{2}{*}{6} & SG & 43.46 & 22.63 & 40.00 & 10.00 & 95.00 & \multirow{2}{*}{$0.006^{*}$} \\
\hline & CG & 30.54 & 21.11 & 25.00 & 0.00 & 80.00 & \\
\hline \multirow{2}{*}{8} & SG & 41.09 & 24.96 & 37.50 & 5.00 & 100.00 & \multirow{2}{*}{$0.034^{*}$} \\
\hline & CG & 30.33 & 23.03 & 22.50 & 5.00 & 85.00 & \\
\hline \multirow{2}{*}{10} & $S G$ & 58.59 & 27.30 & 55.00 & 10.00 & 95.00 & \multirow{2}{*}{$0.020^{*}$} \\
\hline & CG & 45.98 & 23.51 & 40.00 & 5.00 & 95.00 & \\
\hline \multirow{2}{*}{12.5} & SG & 67.93 & 24.05 & 80.00 & 5.00 & 85.00 & \multirow[b]{2}{*}{$0.005^{\star}$} \\
\hline & CG & 53.80 & 22.81 & 52.50 & 0.00 & 85.00 & \\
\hline \multirow{2}{*}{14} & $S G$ & 56.85 & 16.65 & 65.00 & 0.00 & 65.00 & \multirow{2}{*}{0.535} \\
\hline & CG & 54.67 & 16.85 & 65.00 & 0.00 & 65.00 & \\
\hline
\end{tabular}

Caption: CG: control group; SG: study group; SD: standard deviation; * - statistically significant value at the level of $5 \%(p<0.05)$. Statistical tests: Two-proportion Z-test; Wilcoxon signed-rank test; Mann-Whitney test; parametric Student's $t$-test.

The observation revealed statistically significant differences between the groups at the $3000,6000,8000$, 10,000 , and $12,500 \mathrm{~Hz}$ frequencies in the pure-tone threshold audiometry. The comparison of the 46 ears in the $S G$ and the 46 ears in the $C G$ in relation to the pure-tone auditory thresholds obtained in the pure-tone threshold audiometry is presented in Figure 1. 


\section{Frequency (kHz)}

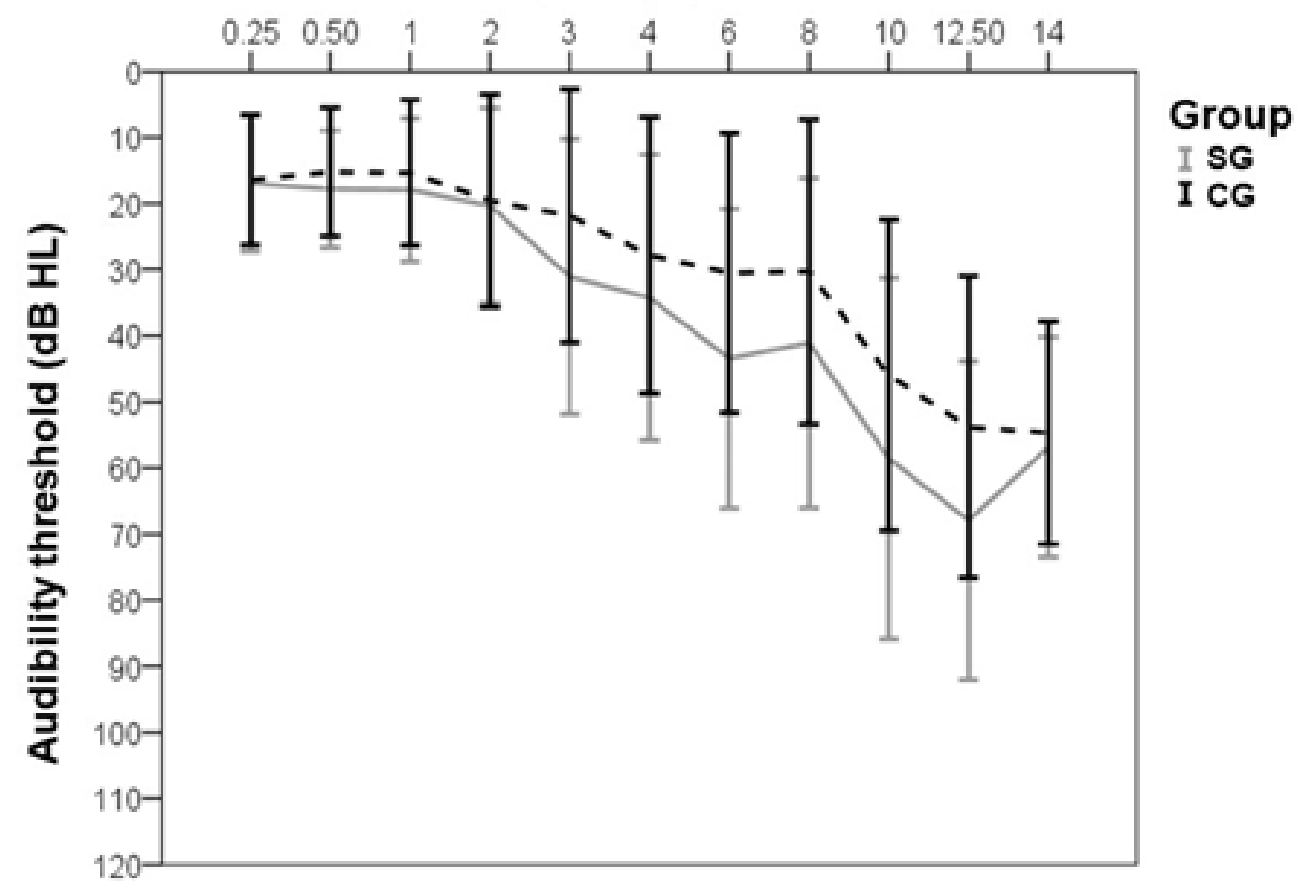

Caption: SG: Study Group; CG: Control Group.

Figure 1. Comparison of the means and standard deviations of the pure-tone auditory thresholds, in $\mathrm{dB} \mathrm{HL}$, obtained in the pure-tone threshold audiometry between the Study Group and Control Group

No statistically significant differences were observed between the groups for the percentage of correct answers in the WRS with monosyllable words $(p=$ 0.508), using the Student's $t$-test and Mann-Whitney U-test to compare the groups. The SG presented a performance of $90.13 \%$ on average, with a standard deviation of $13.59 \%$; the CG's performance was $91.83 \%$, with a standard deviation of $12.39 \%$. The median was $96 \%$ for both groups.
In the sequence, the comparative table between SG and $C G$ in the transient-evoked otoacoustic emissions, using Student's $t$-test, is presented (Table 3).

No statistically significant differences were observed between the groups for any of the parameters assessed in the TEOAE research. Thus, in this study's sample, both the $S G$ and $C G$ had a similar performance in the TEOAE research. 
Table 3. Descriptive comparison measures between Study Group and Control Group regarding response amplitude based on the signalto-noise ratio in the research of transient-evoked otoacoustic emissions

\begin{tabular}{|c|c|c|c|c|c|c|c|c|}
\hline TEOAE & Group & $\mathbf{N}$ & $\begin{array}{c}\text { Mean response } \\
\text { amplitude of the } \\
\text { TEOAE }\end{array}$ & SD & Median & Minimum & Maximum & p-value \\
\hline \multirow{2}{*}{$\begin{array}{l}\text { General } \\
\text { response } \\
\text { (dB) }\end{array}$} & $S G$ & 36 & $\begin{array}{c}8.42 \\
(6.88-9.98)\end{array}$ & $\begin{array}{c}5.42 \\
(4.35-6.24)\end{array}$ & $\begin{array}{c}8.80 \\
(7.20-10.70)\end{array}$ & 0.00 & 20.50 & \multirow[b]{2}{*}{0.810} \\
\hline & CG & 37 & $\begin{array}{c}8.15 \\
(6.58-9.74)\end{array}$ & $\begin{array}{c}5.32 \\
(4.30-6.20)\end{array}$ & $\begin{array}{c}8.65 \\
(7.60-10.00)\end{array}$ & 0.00 & 19.60 & \\
\hline \multirow{2}{*}{$\begin{array}{l}\text { Response } \\
\text { for the } 1 \mathrm{kHz} \\
\text { (dB) band }\end{array}$} & $S G$ & 37 & $\begin{array}{c}9.48 \\
(7.58-11.33)\end{array}$ & $\begin{array}{c}6.58 \\
(5.32-7.59)\end{array}$ & $\begin{array}{c}10.50 \\
(7.00-12.50)\end{array}$ & 0.00 & 24.60 & \multirow{2}{*}{0.575} \\
\hline & CG & 38 & $\begin{array}{c}8.76 \\
(7.12-10.42)\end{array}$ & $\begin{array}{c}5.74 \\
(4.73-6.57)\end{array}$ & $\begin{array}{c}8.20 \\
(7.10-9.80)\end{array}$ & 0.00 & 19.00 & \\
\hline \multirow{2}{*}{$\begin{array}{l}\text { Response } \\
\text { for the } 2 \mathrm{kHz} \\
\text { (dB) band }\end{array}$} & $S G$ & 37 & $\begin{array}{c}9.07 \\
(7.13-10.97)\end{array}$ & $\begin{array}{c}6.80 \\
(5.52-7.73)\end{array}$ & $\begin{array}{c}8.75 \\
(5.70-11.20)\end{array}$ & 0.00 & 24.60 & \multirow{2}{*}{0.231} \\
\hline & CG & 34 & $\begin{array}{c}7.49 \\
(5.78-9.16)\end{array}$ & $\begin{array}{c}5.69 \\
(4.64-6.58)\end{array}$ & $\begin{array}{c}7.50 \\
(6.20-9.20)\end{array}$ & 0.00 & 20.30 & \\
\hline \multirow{2}{*}{$\begin{array}{l}\text { Response } \\
\text { for the } 3 \mathrm{kHz} \\
\text { (dB) band }\end{array}$} & $S G$ & 28 & $\begin{array}{c}7.75 \\
(5.58-10.04)\end{array}$ & $\begin{array}{c}7.76 \\
(6.15-9.14)\end{array}$ & $\begin{array}{c}8.15 \\
(0.00-11.10)\end{array}$ & 0.00 & 27.20 & \multirow{2}{*}{0.586} \\
\hline & CG & 31 & $\begin{array}{c}6.97 \\
(5.30-8.69)\end{array}$ & $\begin{array}{c}5.76 \\
(4.91-6.42)\end{array}$ & $\begin{array}{c}7.20 \\
(5.40-9.70)\end{array}$ & 0.00 & 18.50 & \\
\hline \multirow{2}{*}{$\begin{array}{l}\text { Response } \\
\text { for the } 4 \mathrm{kHz} \\
\text { (dB) band }\end{array}$} & $S G$ & 27 & $\begin{array}{c}4.91 \\
(3.06-6.94)\end{array}$ & $\begin{array}{c}6.85 \\
(4.05-8.82)\end{array}$ & $\begin{array}{c}3.35 \\
(0.00-3.95)\end{array}$ & 0.00 & 27.60 & \multirow{2}{*}{0.966} \\
\hline & CG & 31 & $\begin{array}{c}4.97 \\
(3.73-6.31)\end{array}$ & $\begin{array}{c}4.48 \\
(3.66-5.14)\end{array}$ & $\begin{array}{c}4.20 \\
(3.20-6.40)\end{array}$ & 0.00 & 15.00 & \\
\hline
\end{tabular}

Statistical tests: Student's $t$-test for independent samples and confidence interval of $95 \%$ in the parentheses, with upper and lower limits. Legend: CG: control group; SG: study group; SD: standard deviation; TEOAE: transient-evoked otoacoustic emissions; N: Number of responses in the presence of transient-evoked otoacoustic emissions.

\section{DISCUSSION}

In this study, 23 patients with a positive history of head and neck cancer submitted to chemotherapy and/ or radiotherapy were assessed. Also, a control group was formed with 23 individuals matched for gender and age.

The age range encompassed in the study went from 32 to 80 years, with a mean age of 59 years - i.e., an adult population. The sample had a predominance of males, as there were 9 women (39.1\%) and 14 men $(60.9 \%)$ (Table 1). The characteristics of the sample were compared with the data in the literature, and an agreement was observed regarding age and gender for head and neck cancer. According to data from the American Cancer Society ${ }^{25}$, this type of neoplasia affects predominantly the age group above 50 years, in a proportion of four men to one woman.

The predominant treatments in the sample were the combined radiotherapy and chemotherapy (34.8\%), and chemotherapy alone $(34.8 \%)$, whereas there were
$30.4 \%$ of radiotherapy alone (Table 1). According to the literature, the ideal treatment must be defined by consensus between the head and neck surgeon, the oncologist, and the radiotherapist. They must determine the best therapeutic option according to the type, place, and severity of the tumor, and avoid unnecessary procedures ${ }^{2}$.

Moreover, Menezes ${ }^{26}$ observed that when the patient is submitted to the combined treatment (i.e., chemotherapy and radiotherapy), the chances of alteration in the audiometric threshold is potentialized, as opposed to what happens when either treatment is used alone. In this research, regarding the descriptive comparison measures of pure-tone auditory thresholds between the study and control groups, quantitatively, statistically significant values were observed at the 3000,6000, $8000,10,000$, and $12,500 \mathrm{~Hz}$ frequencies, with worse thresholds in the study group (Table 2).

Qualitatively, the auditory thresholds of the individuals in the study group were compared to those 
of the control group, and an increase was observed in most of the high frequencies. Such results are similar to the data from Fausti et al. ${ }^{16}$, Littman et al. ${ }^{19}$, Yardley et al. ${ }^{20}$, Jacob et al. ${ }^{15}$, and Schultz et al. ${ }^{14}$, who reported the auditory alteration caused by ototoxic medications that impaired the high frequencies on the base of the cochlea, with possible evolution to the apex, posteriorly impairing the medium and low frequencies. Such findings reinforce that medication ototoxicity in combination with radiation can lead to irreversible hearing loss, either early or late, after the treatment has finished.

Furthermore, Almeida et al. ${ }^{21}$ observed that the patients who were submitted to cisplatin chemotherapy in combination with other chemotherapeutic drugs had auditory alterations even at $1000 \mathrm{~Hz}$, and more significant impairment beginning at $6000 \mathrm{~Hz}$. Likewise, in this study significantly worse auditory alterations were observed in the comparison with the control group beginning at $6000 \mathrm{~Hz}$ (Table 2).

The authors ${ }^{15,21}$ also reported that in the comparison of results between conventional pure-tone audiometry and high-frequency audiometry, this last one was more sensitive to early detect auditory alterations. Nevertheless, this study revealed (Table 2) that the conventional audiometry had been sensitive to early detect auditory alterations, which was observed with the diagnosis of hearing loss beginning at the $3000 \mathrm{~Hz}$ frequency.

Regarding the speech recognition percentage index, neither group presented quantitative alteration, corroborating the findings of the pure-tone threshold audiometry. No statistically significant differences were observed between the groups for the percentage of right answers in the WRS with monosyllable words. These results are compatible with pure-tone threshold alterations in both groups. Authors ${ }^{17}$ pointed out that the impairment caused by chemotherapy occurs predominantly at the high frequencies - which, with the intensity used to apply the test $(40 \mathrm{~dB} S \mathrm{~S}$ above the three-frequency mean), does not significantly impair speech.

Almeida et al. ${ }^{21}$ presented results of the distortionproduct otoacoustic emissions research that agreed with the thresholds found in the pure-tone audiometry. As for this study, when the descriptive measures of the transient-evoked otoacoustic emissions were compared between the study and control groups, quantitatively, no statistically significant differences were observed between the groups for any of the parameters assessed by the TEOAE research. Hence, in this study's sample, both the $S G$ and the $C G$ had similar performance in the TEOAE research (Table 3), revealing responses with lower signal-to-noise ratio at the high frequencies (3000 and $4000 \mathrm{~Hz}$ ) when compared with the other frequencies. In contrast with the described studies, this one presented pure-tone threshold alteration beginning at $3000 \mathrm{~Hz}$; however, it did not reveal alteration in the assessment of the outer hair cells functioning.

Nonetheless, Garcia et al. ${ }^{12}$, who monitored the TEOAE in patients with osteosarcoma treated with cisplatin, found an increase in the high-frequency auditory thresholds and response amplitude in the low-level otoacoustic emissions. Garcia et al. ${ }^{12}$ described an increase in the amplitude of the emissions when compared with the signal-to-noise ratio between the doses of cisplatin, after a small dosage of cisplatin, probably due to the chemical changes (calcium and magnesium metabolism) caused by cisplatin in the hair cells. This leads to an increase in the intracellular level of calcium as a consequence of the absence of its antagonist (the magnesium), increasing the permeability of the cytoplasmatic membrane. This mobility of the hairs in the outer hair cells depends on the intracellular calcium. Hence, it can cause an increase in the otoacoustic emissions - which can be an initial indication of a lesion in (and posterior death of) the cell.

The ototoxicity caused by chemotherapy $9,11,12,15,17,19-21,27$ and radiotherapy $8,10,14,26,28$ is a serious issue, which could set a limit to the dosage $e^{12,27,28}$. Although influenced by such factors as the age and initial hearing conditions (before making use of the medications), there is also an influence from the genes related to processing the medications. Hence, the pharmacogenetics can have an impact on each patient's toxicity ${ }^{28}$.

In this study, the cumulative dosage of head and neck cancer chemotherapy of the adults was not controlled. Nevertheless, the TEOAE response was observed, which can mean that an alteration in calcium and magnesium metabolism may be taking place - made evident by the presence of responses in the emission assessment even with the audiological impairment observed in the pure-tone audiometry.

In conclusion, it is verified that the pure-tone audiometry is the most sensitive test in terms of audiological assessment to identify chemotherapy-induced hearing impairment due to head and neck cancer in adults, especially at the $3000,6000,8000,10,000$, and $12,500 \mathrm{~Hz}$ frequencies. However, there were responses in the electroacoustic assessment, indicating that 
chemotherapy alters the calcium and magnesium metabolism, which in turn leads to an increase in the responses in the transient-evoked otoacoustic emissions. Thereby, it is not possible to identify audiological alterations assessing the functioning of the outer hair cells.

This study's limitation was the control of the medication used for the different types of intervention in head and neck cancer treatment. Nonetheless, considering the findings in the research, it is relevant to have periodical audiological follow-ups of the patients submitted to chemotherapy and/or radiotherapy especially those who did not present pretreatment auditory alterations, or who reported auditory complaints during the treatment.

\section{CONCLUSION}

Given the above, it is concluded that individuals with a history of head and neck cancer have higher pure-tone auditory thresholds than their controls, particularly at high frequencies beginning at 3000 $\mathrm{Hz}$. Hence, bilateral sensorineural hearing loss is characterized, with a down-slope configuration. This evidences the deleterious effect of ototoxicity on the peripheral auditory system of adults, especially in its base, observed with a greater impairment in the highfrequency audiometry. The speech recognition is compatible with the alterations in these individuals; the otoacoustic emissions assessment, with the technique used in this study, did not demonstrate statistically significant differences in patients with a history of head and neck cancer submitted to chemotherapy and/or radiotherapy.

\section{REFERENCES}

1. Lydiatt WM, Patel SG, O'Sullivan B, Brandwein MS, Ridge JA, Migliacci JC et al. Head and neck cancers - major changes in the American Joint Committee on Cancer Eighth Edition Cancer Staging Manual. CA Cancer J Clin. 2017;67(2):122-37.

2. Instituto Nacional de Câncer José Alencar Gomes da Silva, Copyright (C) 1996 - 2016 INCA Ministério da Saúde. [cited 2019 Jul18] Available from: http://www2.inca.gov.br/wps/wcm/connect/ tiposdecancer/site/home/laringe

3. Licitra L, Bernier J, Grandi C, Locati L, Merlano M, Gatta G, Lefebvre JL. Cancer of the larynx. Critical Reviews in Oncology/hematology. 2003;47(1):65-80.
4. Wünsch $V$. The epidemiology of laryngeal cancer in Brazil. Sao Paulo Med. J. 2004;122(5):188-94.

5. Vilar CMC, Martins IM. Câncer de cabeça e pescoço. In: Vieira SC, Lustosa AML, Barbosa CNB, Teixeira JMRT, Brito LXE, Soares LFM et al. (eds). Oncologia básica. 1. ed. Teresina, PI: Fundação Quixote, 2012. p.9-22.

6. Vilar CMC, Martins IM. Princípios de cirurgia oncológica. In: Vieira SC, Lustosa AML, Barbosa CNB, Teixeira JMRT, Brito LXE, Soares LFM et al. (eds). Oncologia básica. 1. ed. Teresina, PI: Fundação Quixote, 2012. p.221-36.

7. Crisanto MLLP. Princípios de Quimioterapia. In: Vieira SC, Lustosa AML, Barbosa CNB, Teixeira JMRT, Brito LXE, Soares LFM, Ferreira MAT et al. (eds). Oncologia básica. 1. ed. Teresina, PI: Fundação Quixote, 2012. p.237-52.

8. Oliveira PF, Oliveira CS, Andrade JS, Santos TFC, Oliveira-Barreto AC. Tratamento oncológico na determinação das alterações auditivas. Braz. j. otorhinolaryngol. 2016;82(1):65-9.

9. Rosenberg B, Van Camp L, Krigas T. Inhibition of cell division in escherichia coli by electrolysis products from a platinum electrode. Nature. 1965;205(4972):698-9.

10. Abdollahi H, Mostafaei S, Cheraghi S, Shiri I, Mahdavi SR, Kazemnejad A. Cochlea CT radiomics predicts chemoradiotherapy induced sensorineural hearing loss in head and neck cancer patients: A machine learning and multi-variable modeling study. Phys Med. 2018;45:192-7.

11. Hyppolito MA, Oliveira JAA. Ototoxicidade, otoproteção e autodefesa das células ciliadas da cóclea. Medicina. 2005;38(3/4):279-89.

12. Garcia AP, lório MCM, Petrilli AS. Monitoramento da audição de pacientes expostos à cisplatina. Rev. Bras. Otorrinolaringol. 2003;69(2):215-21.

13. Ng SP, Pollard C, Berends J, Ayoub Z, Kamal $M$, Garden AS et al. Usefulness of surveillance imaging in patients with head and neck cancer who are treated with definitive radiotherapy. Cancer. 2019;125(11):1823-9.

14. Schultz C, Goffi-Gomez MV, Liberman PH, Carvalho AL. Report on hearing loss in oncology. Braz. j. otorhinolaryngol. 2009;75(5):634-41.

15. Jacob LCB, Aguiar FP, Tomiasi AA, Tschoeke SN, Bitencourt RF. Monitoramento auditivo na ototoxidade. Rev. Bras. Otorrinolaringol. 2006;72(6):836-44. 
16. Fausti SA, Frey RH, Henry JA, Olson J, Schaffer HI. High-frequency testing techniques and instrumentation for early detection of ototoxicity. Journal Rehabilitation Res Development. 1993;30(3):333-41.

17. Damian PI, Valverde TA, Guimarães DP, Gil D. Auditory monitoring in adults undergoing chemotherapy with carboplatin. Distúrb Comum. 2017;29(3):438-47.

18. Dunckley KT, Dreisbach LE. Gender effects on high-frequency distortion product otoacoustic emissions in humans. Ear Hear. 2004;25(6):554-64.

19. Littman TA, Magruder A, Strother DR. Monitoring and predicting ototoxic damage using distortionproduct otoacoustic emissions: pediatric case study. J Am Acad Audiol. 1998;9(4):257-62.

20. Yardley MP, Davies CM, Stevens JC. Use of transient evoked otoacoustic emissions to detect and monitor cochlear damage caused by platinumcontaining drugs. Br J Audiol. 1998;32(5):305-16.

21. Almeida EOC, Costa CB, Oliveira SRT, Umeoka MTH. Audiometria tonal e emissões otoacústicas - produtos de distorção em pacientes tratados com cisplatina. Arq. Int. Otorrinolaringol. 2006;10(3):203-8.

22. American Speech-Language-Hearing Association. (1988). Determining threshold level for speech [Guidelines]. [cited 2019 Nov29] Available from: www.asha.org/policy.

23. Lloyd L, Kaplan H. Audiometric interpretation: a manual of basic audiometry. Press, 1978.

24. Finitzo T, Albright $\mathrm{K}$, Oneal J. The newborn with hearing loss: detection in the nursery. Pediatrics. 1998;102(6):1452-60.

25. American Cancer Society. Clinical Oncology. Atlanta: ACS; 2001.

26. Menezes M. Efeitos da radioterapia sobre a audição em pacientes portadores de tumores de cabeça e pescoço [monografia]. Recife (PE): CEFAC; 1999.

27. Yasui N, Adachi N, Kato M, Koh K, Asanuma S, Sakata $\mathrm{H}$ et al. Cisplatin-induced Hearing Loss. J Pediatr Hematol Oncol. 2014;36(4):e241-5.

28. Driessen CML, Leijendeckers J, Snik A, Graaf WTA, Boer JP, Gelderblom $\mathrm{H}$ et al. Ototoxicity in locally advanced head and neck cancer patients treated with induction chemotherapy followed by intermediate or high-dose cisplatinbased chemoradiotherapy. Head \& Neck. 2019;41(2):488-94. 